\title{
How Do Scientists Reach Their Target Audience? Academic and Popular Science Articles in Nutrition
}

\author{
Mavadat Saidi ${ }^{*}$, Masoomeh Saiedi ${ }^{2}$ \\ 1- Shahid Rajaee Teacher Training University, Tehran, Iran \\ 2- Alzahra University, Tehran, Iran
}

\section{A B S T R A C T}

The aim of the current study was to investigate frequencies of interactional metadiscourse markers in English academic research and popular science articles in nutrition. A total of 60 English articles published in three popular databases and four academic journals were analyzed for interactional metadiscourse markers, including hedges, boosters, attitude markers, engagement markers and self-mentions. Results of the analysis revealed nearly twice as many interactional metadiscourse markers in the academic research articles, indicating a higher level of explicit interaction in that genre. Results of the chi-square test $(p \leq 0.01)$ demonstrated that uses of metadiscourse markers differed significantly in the two genres. Findings showed that the authors of academic research and popular science articles tried to create balances between highlighting the significance and pinpointing the tentativeness of the claims and, thereby, they made interactive choices to approximate their readers' world. Furthermore, results highlighted the high relevance of popular science articles to academic research articles since authors were inevitably involved in transforming and recovering scientific findings into more comprehensive accounts in popular science texts. Findings can be transferred to pedagogical grounds through raising students' awareness in English writing courses about the way; through which, the authors of academic research and popular science articles use interactional resources to enhance quality and efficiency of their interactions with the readers.

Keywords: Academic research articles, Interactional metadiscourse, Nutrition, Popular science articles

\section{Introduction}

\section{Background}

Although scientists take advantages of academic papers as tools for creating new knowledge (1) that is used by the academic community members, public rights to be informed of the scientific findings and technical developments seem utmost significant to enhance scientific literacies of the society members (2). This urges transforming scientific concepts and findings into meaningful pieces of information (1). Within the last decades, not only public rights to know about the scientific outcomes, but also the scientists' willingness to share their excitements about science and their experiences and ideas (3) to achieve a wider range of audiences (2) have increased popularization of science. Professional and popular texts present science differently to different groups of audiences, scholarly and nonscholarly (4). Indeed, academic writers should moderate technical levels of their writing and gear it to intended audiences. Therefore, metadiscourse that reveals presence of the hearer/reader in the texts seems to be a tool to see the walk from the readers' perspectives (5) and helps writers provide their audiences with moderated scientific information, which are comprehensible to those who may lack the necessary technical knowledge. As Hyland (2015) asserted "popular science articles are most obviously distinctive in their use of interactional metadiscourse", metadiscourse contributes to understand the interpersonal function of academic texts. Technically, not only writers use various forms of argumentations, but also they take advantages of a wide range of interactional resources to inform and persuade their non-expert audiences (6). Therefore, the aim of the current study was to investigate distribution of interactional metadiscourse in English academic and popular science articles in nutrition to show how interactions between the writers and the readers were managed through use of interactional metadiscourse markers. By the analysis of interactional metadiscourse, as one of the most enduring and comprehensive models of interpersonality (6), writers' views towards their readers were revealed in the two genres. 


\section{Science popularization in literatures}

Science popularization as a social phenomenon (2) tries to disseminate knowledge outside the academic discourse communities, transferring scientific findings to everyday discourses (7). Scientists are enthusiastic to share their findings with the society through user-friendly ways (1, 3). Popularization allows scientists to fulfill this desire through reconstructing scientific outcomes for nonscholarly audiences (8) to convince them with the significance of content and ideology of the scientific advancements (9). Through popularization of the scientific outcomes, scientists serve critical roles in forming public views of academic research (6). Since its primary introduction, popularization of science has particularly been interested. Nwogu (1991) investigated discourse structures of the journalistic versions of research articles. Miller (1998) described that visual elements played informative and persuasive roles in academic texts while they served luxurious and explanatory roles in popular academic texts. In another study, Bucchi (2013) analyzed contents of popular Italian newspapers published over 15 years. Parkinson and Adendroff (2004) took advantage of popular science articles in teaching scientific literacy in English for specific purpose courses of scientific writing. They warned against merely using popular articles that could not be considered as models for scientific writing due to their extreme emphasis on human participants, use of active voices and citing other scholars in non-academic styles. Giannoni (2008) investigated generic features of popularization in 40 editorials in medicine and applied linguistics and found such popularizing features as personalization, contingency and humor. Hyland (2010) explored a corpus of popular science articles and concluded that journalistic versions of research articles strived to help non-specialist audiences understand research findings. More recently, Estrada and Davis
(2015) highlighted roles of images in popularizing scientific outcomes. Riesch (2015) stated effectiveness of using humor in public scientific discourse. In a more recent study, Babaii, Atai and Saidi (2017) analyzed 40 English popular science articles in nutrition for appraisal resources and concluded that popular science authors were more inclined to include their feelings about their outcomes and meet expectations of their intended audiences within non-academic groups through use of evaluative resources.

\section{Metadiscourse in literatures}

Introduction of the metadiscourse concept by Zellig Harris (1959) and its further development in applied linguistics led to the researchers' interests in exploring the concept in various genres within various disciplines and languages. Metadiscourse includes linguistic elements that convey interpersonal and/or textual meanings (18). It untangles the way; by which, languages are used to gear with the readers' comprehension levels (19). While textual metadiscourse helps writers connect various ideational meanings, interpersonal metadiscourse provides the authors with opportunities to express their personalities, their evaluation of and attitudes toward ideational materials and depict the author roles in communication processes and their intended audience reactions (20). According to Hyland (2004), metadiscourse entails selfreflexive linguistic expressions referring to evolving texts, writers and imagined readers of the texts. Among numerous models of metadiscourse, the interpersonal model of metadiscourse proposed by Hyland (2004, 2005) seems to include functional approaches. The model distinguishes interactive and interactional resources. The former resources are linked to discourse organizations while the latter is associated to the writers' efforts to set up appropriate relationships to their data, arguments and audiences (Table 1) (5).

Table 1. The interpersonal model of metadiscourse (Hyland, 2005)

\begin{tabular}{|c|c|c|}
\hline & Function & Example \\
\hline Interactive resources & Help to guide reader through the text & \\
\hline Transitions & Express semantic relation between main clauses & in addition/ but/ thus/ and \\
\hline Frame markers & Refer to discourse acts, sequences, or text stages & finally/ to conclude/ my purpose is \\
\hline Endophoric markers & Refer to information in other parts of text & noted above/ see Fig/ in section 2 \\
\hline Evidentials & Refer to source of information from other texts & according to $\mathrm{X} /(\mathrm{Y}, 1990), \mathrm{Z}$ states \\
\hline Code glosses & Help readers grasp meanings of ideational material & namely/ e.g./ such as/ in other words \\
\hline Category & Function & Examples \\
\hline Interactional resources & Involve the reader in the argument & \\
\hline Hedges & Withhold writer's full commitment to proposition & might/ perhaps/ possible/ about \\
\hline Boosters & Emphasize force or writer's certainty in proposition & in fact/ definitely/ it is clear that \\
\hline Attitude markers & Express writer's attitude to proposition & unfortunately/ I agree/ surprisingly \\
\hline Engagement markers & Explicitly refer to or build relationship with reader & consider/ note that/ you can see that \\
\hline Self-mentions & Explicit reference to author(s) & I/ we/ my/ our \\
\hline
\end{tabular}


Research article subsections such as introductions (23) and abstracts (24) and textbook (21) articles, handbook chapters, textbook chapters and introductory textbooks in applied linguistics (25) have been studied for metadiscourse markers. In addition to academic registers, metadiscourse has been explored in studies focusing on news media and business communications (26, 27). Dafouz-Milne (2008) studied distributions of metadiscourse in opinion columns in The Times and El Pais. Yao (2012) compared Chinese and English news commentaries for metadiscourse. Similar to the current study, Fu and Hyland (2014) studied popular articles and opinion texts and found that the two genres were significantly different for the use of interactional metadiscourse markers. Moreover, the opinion texts included a higher number of engagement markers, boosters and self-mentions to clearly present authors' views and gear to the intended readers' expectations.

\section{Purpose of the study}

Notwithstanding the extensive literatures on use and distribution of metadiscourse markers in various academic texts in general and research articles in particular, Hyland (2017) has recently advised scholars of the danger of confining interpersonal models of metadiscourse to limit the text types and called for further research to unveil potentials of metadiscourse in providing valuable insights into interactions between the writers and the readers. The current study has contributed to this line of research by studying academic research and popular science articles in nutrition for the interpersonal models of metadiscourse.

\section{Methods}

\section{Corpus}

Corpus of the study consisted of 60 English articles, including 30 academic research and 30 popular science articles with a total of 104,144 words $(88,561$ words in English academic research articles and 15,583 words in English popular science articles). List of the academic and popular sources was prepared using the expert judgments of associate professors and $\mathrm{PhD}$ students of nutrition. First, a comprehensive list of professional journals in nutrition was collected from www.journals.cambridge.org, www.online.sagepub.com, www.sceincedirect.com and www.en.wikipedia.org/wiki/List_of_sceintific_journals $\neq \mathrm{N}$ utrition. Then, expert judgments were carried out based on the comments from four associate professors with research experiences of more than ten years and currently active in nutrition as well as five $\mathrm{PhD}$ students with research experiences of more than three years. The experts were asked to add other nutrition journals with high impact factors to the list. They also were requested to write the list of English popular sources; in which, experts write articles for non-expert audiences. A new list was prepared, including common professional and popular sources; on which, the experts had consensus. The new list was provided to two associate professors and five $\mathrm{PhD}$ students to be reviewed for the last time. They ranked the journals, magazines and newspapers of the list. Four English professional journals and three English popular science sources were chosen for sampling of the academic and popular science sources. It is noteworthy that the academic journals with the highest ranks were selected using their ranking by the experts in the prepared list and their impact factors. The four selected English professional journals were Public Health Nutrition, The Journal of Nutrition, American Journal of Clinical Nutrition and European Journal of Clinical Nutrition and the three selected English popular science sources were WebMD, New York Times and Science Daily. For the sake of time (11), 60 articles published from 2010 to 2015 were randomly selected from the archives of popular science and academic sources.

\section{Procedures and data analyses}

First, each article was analyzed to code the interactional metadiscourse markers based on Hyland's interpersonal model of metadiscourse (2005). Whole texts of the popular science articles, representing findings and relevant explanations, were studied (9), whereas only the results and discussion sections of the academic research articles were studied (31). This was because results and discussion sections of academic research articles included the best representations for the physical evidence of the research. These two sections established validity of the findings and reported outcomes of the scientific procedures and the possible reasons justifying them. All categories of the interactional metadiscourse were coded by the researcher and another coder and an inter-coder reliability of 0.92 was achieved. Calculating frequencies of each category of the interactional metadiscourse, raw frequencies were normalized to 1000 words to make the academic research and popular science articles of various lengths comparable (32). For the normalization, each raw frequency was divided by the number of words in that corpus and multiplied by the basis chosen for norming (1000) (33). Then, statistical non-parametric test of Chi-square was carried out to show if there were significant differences between the English academic research articles and the popular science articles for different categories of the interactional metadiscourse.

\section{Results}

Table 2 displays the frequency counts that indicate how interactional metadiscourse markers were distributed in English academic research and popular science articles. 
Mavadat Saidi and Masoomeh Saiedi: Academic and popular science articles in the field of nutrition

Table 2. Frequencies of the interactional metadiscourse markers in English academic and popular science articles

\begin{tabular}{|c|c|c|c|c|c|c|c|}
\hline Articles & Frequency & Hedge & Booster & Attitude Marker & Engagement Marker & Self-mention & Total \\
\hline \multirow{2}{*}{ Academic research articles } & Raw & 522 & 186 & 27 & 0 & 233 & 968 \\
\hline & Normalized & 5.012 & 1.785 & 0.259 & 0 & 2.237 & 29.294 \\
\hline \multirow[t]{2}{*}{ Popular science articles } & Raw & 311 & 53 & 13 & 10 & 57 & 444 \\
\hline & Normalized & 2.989 & 0.508 & 0.124 & 0.096 & 0.547 & 4.263 \\
\hline
\end{tabular}

Nearly twice as many as interactional metadiscourse markers were detected in the academic research articles, indicating a higher level of explicit interaction in that genre. Results of chi-square test $(p \leq 0.01)$ revealed that the use of metadiscourse markers differed significantly in the two genres (Table 3).

Table 3. Chi-Square test for interactional metadiscourse markers in English academic and popular science articles

\begin{tabular}{llll}
\hline & Value & df & Sig. \\
\hline Academic vs. Popular Articles & 1.412 & 9 & 0.000 \\
\hline
\end{tabular}

Difference was significantly evident in the greater use of hedges, boosters and self-mentions in academic research articles, indicating writers' efforts to adjust their certainty and commitment to the statements as well as simultaneous clear authorial positions. These contradictory results might refer to peculiarity of the academic genres in nutrition. For example, authors might take advantages of hedges and boosters along with selfmentions to negotiate meaning such as various forms of written discourses (6). Examples from the academic research articles are as follows:

\section{Hedges}

(1) ... clinicians might be especially concerned about kindergarten overweight for children with a ... (AJCN, 2015)

(2) Therefore, it is possible that there is a bias in the estimation of the association between diet and obesity. (EJCN, 2010)

(3) ... of a healthy SI might not be as high as the neonates and thus adults would take up a lesser...

(JN, 2013)

\section{Boosters}

(1) ... the reported half glass of juice is really $\% 100$ juice and, moreover ... (PHN, 2011)

(2) There are obviously numerous other combinations of amino acids that ... (JN, 2014)

(3) ... and higher calcium intake were significantly associated with lower ... (EJCN, 2010)

\section{Self-mentions}

(1) Our results imply that modest weight fluctuations in healthy adults lead to ... (AJCN, 2012)

(2) Our data support the evidence that high SF intake does not have a major impact ... (JN, 2014)
Despite existing differences, however, authors of the popular science articles included a large number of hedges, boosters and self-mentions. Examples from the popular science articles are as follows:

\section{Hedges}

(1) You might be tempted to cut back on carbs to help lose the baby weight. (WebMD, 2013)

(2) Calorie restriction .... and may help cells better use antioxidants. (SD, 2015)

Using hedges, authors of the popular science articles might try to highlight uncertainty, where information cannot be confirmed based on the standards of academic validity (6). Nevertheless, the lower number of hedges in popular science articles might indicate authors' tendency to present their statements as the authorized certainties, persuading readers by truth values of the claims. Furthermore, the higher number of hedges in academic research articles might refer to necessity of cautions in research articles (5). Similar to results by $\mathrm{Fu}$ and Hyland (2014), current results revealed use of boosters to remove doubts and highlight significance and uniqueness of the present information (9); as seen in the following examples:

\section{Boosters}

(1) ... there are clearly strategies that can help. (NYT, 2014)

(2) In fact, a 2008 study in The British Journal of Nutrition discovered that 80 percent of raw food eaters fell short of ... (WebMD, 2012)

With a much lower frequency, self-mentions in popular science articles were used to demonstrate authors' personal commitments to the claims as follows:

\section{Self-mentions}

(1) $I$ know that there are some nutrient losses with cooking and processing ... (WebMD, 2012)

(2) We have investigated how the genome of white adipocytes is reprogrammed ... (SD, 2014)

However, the lower number of self-mentions in popular science articles compared to that in academic research articles might be resulted from the authors' more tendency to present information not only as personal judgments, but also as the conclusions of research actors, who provided their claims as results of cutting-edge scientific research (6). Authors of the popular science articles used a pseudoobjective approach in reporting scientific research findings. Results revealed the low frequency of attitude 
markers in academic and popular science articles. Examples of attitude markers in academic research articles are as follows:

\section{Attitude markers}

(1) Surprisingly, there were not effects of the WG intervention on the composition ... (JN, 2014)

(2) Unfortunately, this type of information cannot be obtained from a ... (AJCN, 2011)

Examples of attitude markers in popular science articles are as follows:

\section{Attitude markers}

(1) Unfortunately, nutrient deficiencies and malnutrition can persist for a ... (WebMD, 2009)

(2) But scientific support for that idea has been surprisingly meager .... (NYT, 2014)

As seen in the highlighted examples, same words were used to express the authors' attitudes. However, findings were in contrast to those of Babaii, Atai, \& Saidi (2017); in which, the most frequent category of appraisal theory was the attitude resource in popular science articles. According to White (1998), these features were used to express the authors' feelings towards the products, processes and entities. Use of attitude markers entailed evaluating semiotic and natural phenomena considering value systems of the especial addressed community (35). Furthermore, they are used to convey the accessibility of the materials (6). Indeed, authors of the popular science articles displayed further preferences for following the norms of scientific discourse communities, and thereby, presenting scientific nature of their findings (36). Moreover, engagement markers were absent in academic research articles and the lowest frequent interactional feature in popular science articles. Examples from popular science articles are as follows:

\section{Engagement markers}

(1) Consider how you're doing emotionally, and whether that ... (WebMD, 2014)

(2) Pay attention to the thoughts and feelings you have before ... (WebMD, 2014)

This may be resulted from the roles they serve in recognizing presence of the audiences and establishing relationships with the readers $(37,38)$. The authors of the two genres highlighted their authorial attitudes. This especially occurred in academic research articles and might refer to the authors' tendency to serve the academic norms even in the process of transferring scientific findings to unqualified audiences.

\section{Conclusions}

The current study explored and compared use of interactional metadiscourse markers in English academic research and poplar science articles as two genres with various underlying communicative purposes and intended audiences. Findings indicated that the authors of the two genres tried to establish their own credibility towards the topics and readers through using wide ranges of interpersonal metadiscourse markers (6). While both groups tried to make balances between highlighting the significance and pinpointing the tentativeness of the claims, they made interactive choices to approximate their readers' world. As Fu and Hyland (2014) stated, this might suggest that authors of popular science and academic research articles scientifically argued in the same way. The explicit interactional metadiscourse markers in popular science articles might show that authors decontextualize academic research findings for unqualified audiences and make the findings more accessible by the readers. As quoted by $\mathrm{Fu}$ and Hyland (2014), "authors can afford to persuade by stealth, taking a backseat role to the fascinating discoveries of science itself" (6). Findings might highlight great associations of the popular science articles to academic research articles since the authors were inevitably involved in transforming and recovering scientific findings into further comprehensive accounts. Therefore, this study may point to the existing proximity of academic genres to popular ones in nutrition. Further studies on academic research and popular science articles in various disciplines may further clarify the issue. Results of the present study enhance existing literatures on the interactive dimensions of metadiscourse in academic and popular science articles and can be used by the students, particularly those interested in study of rhetoric discourse analysis as well as critical discourse analysis. Findings can be transferred to pedagogical grounds through raising students' awareness in English writing courses about the ways; by which, authors of the academic research and popular science articles use interactional resources to enhance quality and efficiency of their interactions with the readers (16). As public discourses are still neglected subjects concerning their interactional features $(6,19)$, the current study may rise concerns on the ways; through which, the authors establish relationships with their intended audiences. Hopefully, the current study results in further investigations on how language works as communication (5).

\section{Financial disclosure}

The authors declared no financial interest.

\section{Funding/Support}

No funds were received for this study.

\section{References}

1. Russell N. Communicating Science. Cambridge: Cambridge University Press 2010.

2. Ren F, Zhai J. Communication and Popularization of Science and Technology in China. London: Springer 2013. 
3. Ben-Ari ET. When scientists write books for the public: The ups and downs, ins and outs, of writing popular science books. BioScience 1999; 49: 819-824.

4. Bowler PJ. Science for All: The Popularization of Science in Early Twentieth-Century Britain. Chicago and London: The University of Chicago and London 2009.

5. Hyland K. Metadiscourse. In: Tracy K, Ilie C, Sandel T editors. The International Encyclopedia of Language and Social Interaction. John Wiley \& Sons Inc; 2015: 1-15.

6. Fu X, Hyland K. Interaction in two journalistic genres: a study of interactional metadiscourse. English Text Construction 2014; 7: 122-144.

7. Lievrouw LA. Communication and the social representation of scientific knowledge. Critical Studies in Mass Communication 1990; 7: 1-10.

8. Giannoni DS. Popularizing features in English journal editorials. English for Specific Purposes 2008; 27: 212-232.

9. Hyland K. Constructing proximity: Relating to readers in popular and professional science. Journal of English for Academic Purposes 2010; 9: 116-127.

10. Nwogu KN. Structure of science popularizations: A genreanalysis approach to the schema of popularized medical texts. English for Specific Purposes 1991; 10: 111-123.

11. Miller Th. Visual persuasion: A comparison of visuals in academic texts and the popular press. English for Specific Purposes 1998; 17: 29-46.

12. Bucchi M. Style in science communication. Public Understanding of Science 2013; 22: 904-915.

13. Parkinson J, Adendorff R. The use of popular science articles in teaching scientific literacy. English for Specific Purposes 2004; 23: 379-396.

14. Estrada FCR, Davis LS. Improving visual communication of science through incorporation of graphic design theories and practices into science communication. Science Communication 2015; 37: 140-148.

15. Riesch H. Why did the proton cross the road? Humor and Science Communication. Public Understanding of Science 2015; 24: 768-775.

16. Babaii E, Atai MR, Saidi M. Are scientists objective? An investigation of appraisal resource in English popular science articles. Iranian Journal of Language Teaching Research 2017; 5: 1-19.

17. Harris MAK. The transformational model of language structure. Anthropological Linguistics 1959; 1: 27-29.

18. Vande Kopple WJ. Some exploratory discourse on metadiscourse. College Composition and Communication 1985; 26: 82-93.

19. Hyland K. Metadiscourse: What is it and where is it going? Journal of Pragmatics 2017; 113: 16-29.

20. Vande Kopple WJ. From the dynamic style to the synoptic style in spectroscopic articles in the physical review: Beginnings and 1980. Written Communication 2002; 19: 227-264.

21. Hyland K. Disciplinary Discourse: Social Interactions in Academic Writing. Ann Arbor: University of Michigan Press 2004.
22. Hyland K. Metadiscourse, London: Continuum 2005.

23. Rubio M. A pragmatic approach to the macro-structure and metadiscoursal features of research article introductions in the field of agricultural sciences. English for Specific Purposes 2011; 30: 258-271.

24. Gillaerts P, Van de Velde. Interactional metadiscourse in research article abstracts. Journal of English for Academic Purposes 2010; 9: 128-139.

25. Kuhi B. Generic variations and metadiscourse use in the writing of applied linguistics: a comparative study and preliminary framework. Written Communication 2011; 28: 97-141.

26. Perez FM. Cultural values and their correlation with interactional metadiscourse strategies in Spanish and US business websites. Atlantis 2014; 36: 73-95.

27. Vasquez C. "Don't Even Get Me Started...”: Interactive metadiscourse in online consumer reviews. In Darics $\mathrm{E}$ editor. Digital Business Discourse. Palgrave: London; 2005: 9-39.

28. Dafouz-Milner E. The pragmatic role of textual and interpersonal metadiscourse markers in the construction and attainment of persuasion: Across-linguistic study of newspaper discourse. Journal of Pragmatics 2008; 40: 95113.

29. Yao HQZ. A comparative analysis of the use of metadiscourse in English and Chinese news commentaries. Foreign Language 2008; Accessed on 16 June 2018. Available at: http://en.cnki.com.cn/Article_en/CJFDTotalOUTL201201022.htm.

30. Mur-Duenas P. An intercultural analysis of metadiscourse features in research articles written in English and Spanish. Journal of Pragmatics 2011; 43: 3068-3079.

31. Fahnestock J. Accommodating science: The rhetorical life of scientific facts. Written Communication 1998; 15: 330-350.

32. Biber D, Conrad S, Reppen R. Corpus Linguistics: Investigating Language Structure and Use. Cambridge: Cambridge University Press 1998.

33. Nur Aktas R, \& Cortes V. Shell nouns as cohesive devices in published and ESL student writing. Journal of English for Academic Purposes 2008; 7: 3-14.

34. White PRR. Telling Media Tales: the news story as rhetoric. Unpublished PhD Dissertation. Sydney: University of Sydney 1998.

35. Mur-Duenas P. Attitude markers in business management research articles: a cross-cultural corpus-driven approach. International Journal of Applied Linguistics 2010; 20: 50-72.

36. Abdi R. Interpersonal metadiscourse: an indicator of interaction and identity. Discourse Studies 2002; 4: 139-145.

37. Kim Ch. Personal pronouns in English and Korean texts: a corpus-based study in terms of textual interaction. Journal of Pragmatics 2009; 41: 2086-2099.

38. Proctor $\mathrm{K}, \mathrm{Su}$ LI. The 1st person plural in political discourse-American politicians in interviews and in a debate. Journal of Pragmatics 2011; 43: 3251-3266. 